\title{
Development of a sustainable process for the production of polymer grade lactic acid
}

\author{
Susmit S Bapat, Clint P Aichele* and Karen A High
}

\begin{abstract}
Lactic acid is a commonly occurring substance in nature, ranging from existence in micro-organisms to the human body. Traditionally, lactic acid has applications in industries such as food, chemicals, pharmaceuticals and textiles. In this work, a sustainable process for the production of polymer grade lactic acid (99 wt. \% on dry basis) from crude lactic acid was simulated. The simulation was performed using Aspen Plus ${ }^{\circledR}$ version 8.2. The thermodynamic model used for the process was NRTL - Hayden O'Connell due to the polar nature and non-ideal behavior of the species involved. The process was carried out in three stages. First, crude lactic acid was obtained by reacting calcium lactate with sulfuric acid. The second stage consisted of esterification of lactic acid by reactive distillation. A RadFrac column was used for this purpose which also facilitated easy separation of methyl lactate from methanol and water. Pure methyl lactate obtained from the second stage was then hydrolyzed in the third stage using pure lactic acid as an auto-catalyst to obtain the desired product. Use of pure lactic acid as an auto-catalyst helped to achieve the required purity as it minimized contamination. The process was optimized using sensitivity analysis in Aspen Plus ${ }^{\oplus}$.
\end{abstract}

Keywords: Lactic acid, Process simulation, Reactive distillation, Auto-catalyst, RadFrac, Sensitivity analysis

\section{Introduction}

Lactic acid was first isolated in 1780 by Swedish scientist Carl Wilhelm Scheele by crystallizing its calcium salt [1]. It is a weak organic acid with a hydroxyl group and a carboxylic group present on adjacent carbon atoms in the carbon chain. This duality in structure allows it to react either as an acid or as an alcohol.

Traditionally, lactic acid has applications in the food, chemical, and pharmaceutical industries. In the food industry, lactic acid with a purity of about $85 \mathrm{wt}$. \% is used to induce a sour taste in food products, for example in pickles and sauerkraut. It is also used as an acidulant in the food industry [2]. In addition, it is also used in the textile industry as a caustic [3,4]. Around $80-85$ wt. \% of lactic acid is manufactured for use in the food industry. More recently however, there has been an increased focus on manufacturing lactic acid of high purity ( $99 \mathrm{wt}$. $\%$ on dry basis) which can be used as the monomer for producing poly-lactic acid (PLA). PLA can be obtained from lactic acid via two different mechanisms -1 ) direct polymerization of lactic acid by poly-condensation or 2 )

\footnotetext{
* Correspondence: clint.aichele@okstate.edu

School of Chemical Engineering, Oklahoma State University, Stillwater, OK 74078 , USA
}

condensation to form lactide (intermediate) and corresponding ring-opening polymerization to obtain PLA [3].

PLA is a biocompatible and biodegradable material that has numerous applications in sustainable plastic products [5]. Along with ease of disposal, lactic acid polymers also possess high tensile strength and can be used in the packaging industry and for medical and biological applications [6]. Table 1 summarizes the applications of PLA in various industries [2,7].

PLA competes with traditional plastics like polyethylene terephthalate (PET) and poly propylene (PP) in terms of sustainability [8] and applications. PLA is a biodegradable polymer and decomposes at composting conditions and temperatures above $60^{\circ} \mathrm{C}$. PLA production requires less energy per $\mathrm{kg}$ as compared to PET and PP (42 MJ/kg for PLA as compared to $73 \mathrm{MJ} / \mathrm{kg}$ for PP and $80 \mathrm{MJ} / \mathrm{kg}$ for PET) [8]. Recycling PLA, however, is difficult using traditional mechanical or melt-recycling methods because of its temperature and water sensitivity. To accomplish this, chemical processes which can hydrolyze PLA to lactic acid are being developed.

According to a comparison study performed by Tabone, Cregg et. al., PLA is the top ranked polymer in terms of rankings based on green design principles and ranks sixth 
Table 1 Summary of polymer grade lactic acid applications

\begin{tabular}{|c|c|c|}
\hline Industry & Property & Application \\
\hline Medical & Non-toxic, relatively strong, bio-compatible, sterilizable & $\begin{array}{l}\text { Medical Implants; clinical applications - sutures; meshes, } \\
\text { bone fixation devices }\end{array}$ \\
\hline Packaging & $\begin{array}{l}\text { High tensile strength, thermal resistance, impact resistance, } \\
\text { transparency }\end{array}$ & Flexible Films, thermoforming, lamination \\
\hline Textile & $\begin{array}{l}\text { bacteriostatic, flame-retardant, } \\
\text { and weathering resistance }\end{array}$ & Geo-textiles, Industrial Fabrics, Fibers, Home Furnishings \\
\hline Environmental & Bio-compatible & $\begin{array}{l}\text { As sorbent in wastewater treatment; As a substrate for nitrogen removal; } \\
\text { as a bioremediation agent }\end{array}$ \\
\hline Other & Biodegradability, flame-retardant, thermal resistance & $\begin{array}{l}\text { To manufacture sandbags, weed prevention nets, vegetation nets, } \\
\text { vegetation pots, ropes, binding tape for use in the agriculture industry }\end{array}$ \\
\hline
\end{tabular}

according to Life Cycle Assessment principles [9]. It is therefore considered as one of the more sustainable alternatives to plastics being used currently.

To obtain high quality PLA, polymer grade lactic acid ( 99 wt. \% purity) is the starting point. Several efforts have been made previously to obtain high purity lactic acid [10-12]. Those methods generally have the following limitations.

1. High pressure and temperature required to achieve the intended purity which increases cost.

2. High pressure and temperature also lead to formation of by-products (unwanted methyl esters) during the esterification reaction which are difficult to separate.

3. Use of acid catalyst in the hydrolysis reaction hampers lactic acid purity.

4. Limited conversion for the esterification reaction due to product build-up.

\section{Process description}

The present simulation work is based on a patented process by the National Chemical Laboratory (Pune) to manufacture polymer grade lactic acid [13]. The process can be roughly divided into three stages. The first stage consists of reacting $10 \mathrm{wt}$. \% calcium lactate (obtained as a fermentation product) with concentrated $\mathrm{H}_{2} \mathrm{SO}_{4}$ to yield dilute crude lactic acid and calcium sulfate as shown in Figure 1 . The sulfate is separated out by means of a centrifuge and the crude lactic acid is concentrated to $60 \mathrm{wt}$. \% by passing it through a falling film evaporator.

In the second stage, the dilute lactic acid is sent to the counter-current reactive distillation column or the bubble column where it reacts with rising methanol vapors in the presence of concentrated $\mathrm{H}_{2} \mathrm{SO}_{4}$ to produce methyl lactate and water via the esterification reaction as depicted in Figure 2. Liquid methyl lactate flows to the bottom of the column while water and unreacted methanol vapors move up the column to the distillation section where they are separated. Liquid methyl lactate is then isolated by means of fractional distillation to separate out the methyl lactate by-products of fermentation impurity carboxylic acids to give highly pure methyl lactate ( 98 wt.\%).

In this process, reactive distillation is the most crucial operation on which the entire process is dependent. A reactive distillation operation consists of simultaneous

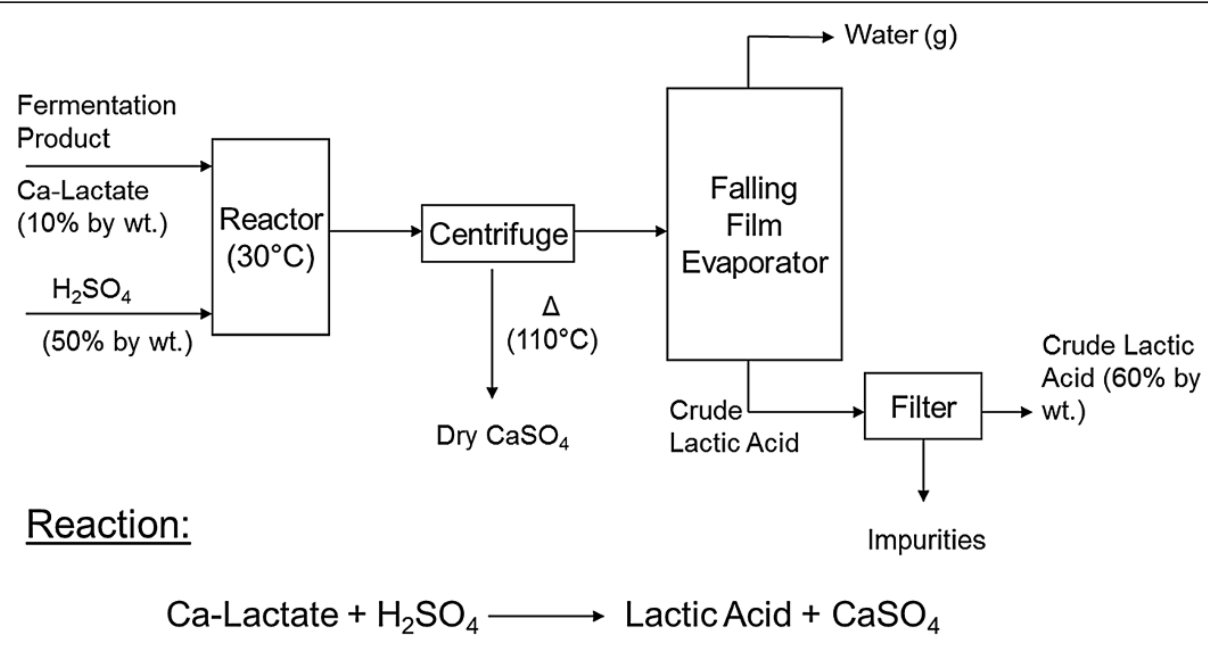

Figure 1 Basic process flow diagram for the first stage of polymer grade lactic acid production. 


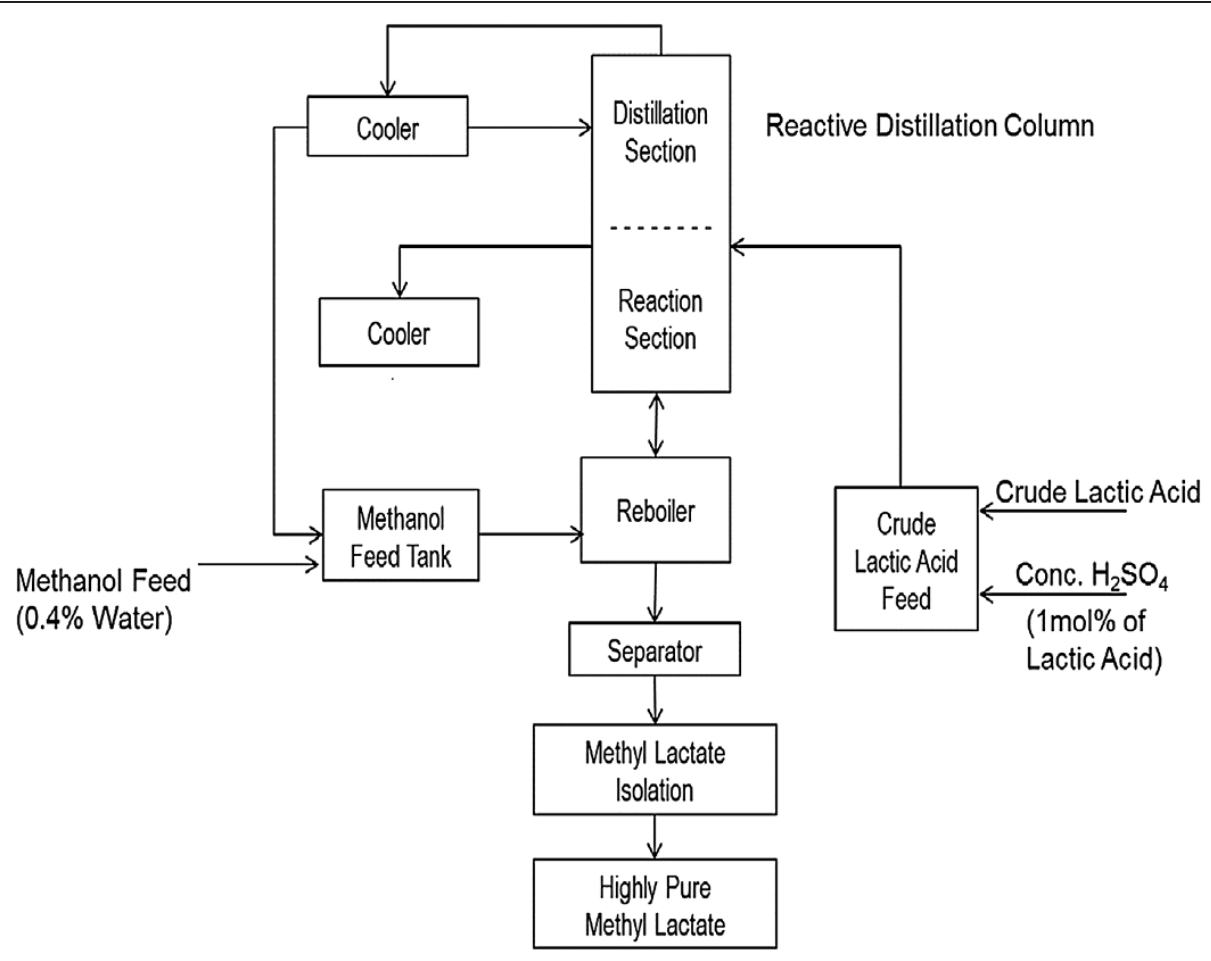

Lactic Acid + Methanol $\stackrel{\text { Conc. } \mathrm{H}_{2} \mathrm{SO}_{4}}{\longrightarrow}$ Methyl Lactate $+\mathrm{H}_{2} \mathrm{O}$

Figure 2 Basic process flow diagram for the second stage of polymer grade lactic acid production.

reaction and separation processes $[14,15]$. In this case, methanol reacts with crude lactic acid to produce methyl lactate. As per the patented process, water and methanol are being simultaneously separated in the same column. However, while simulating this process it was observed that an additional separation column (Separat 4) was more effective for carrying out the separation of methanol and water than having a side-draw from the RadFrac column. It can therefore be said that the Bubble Column Reactor and Separat 4 together represent the Reactive Distillation Column. However, it should be noted that the more significant separation of methyl lactate and water + methanol is still occurring in the Bubble Column Reactor.

As the product (i.e. methyl lactate) is being continuously removed from the reactor the reaction equilibrium shifts towards the product side, thereby increasing maximum conversion according to Le-Chatelier's principle.

This is followed by the third stage which involves hydrolysis of pure methyl lactate to high purity lactic acid (Figure 3). The ingenuity of this stage lies in the fact that pure lactic acid is used as an auto-catalyst to avoid impurities. The use of an auto-catalyst facilitates achieving high lactic acid purity (99 wt. \% on dry basis) and also increases the reaction rate. Also, methanol which is a by-product of the hydrolysis reaction is recycled back to the bubble column, thereby reducing the inventory cost and energy. The design objective for this simulation is to obtain a high yield of polymer grade (99 wt. \% on dry basis) lactic acid as the final product. The process is optimized by varying the stream flow rates and design conditions to come up with the most energy efficient alternative for a given lactic acid output. The process model is created and simulated using Aspen Plus ${ }^{\oplus}$ version 8.2.

It should be noted that the process flow diagrams depicted in Figures 1, 2 and 3 have been retained as per the process described in the patent and should be used for reference purpose only. While performing the simulations certain changes have been made to the process for either simplicity or improved productivity. The final simulated process flow diagram is as per shown in Figure 4.

\section{Design basis}

The design basis was setup based on Example 6 (Control Example) and Example 10 (hydrolysis of methyl lactate to get pure lactic acid) from the patent [13]. The design specifications are listed in Table 2.

\section{Model development}

The following step-wise methodology was adopted while simulating the process. 

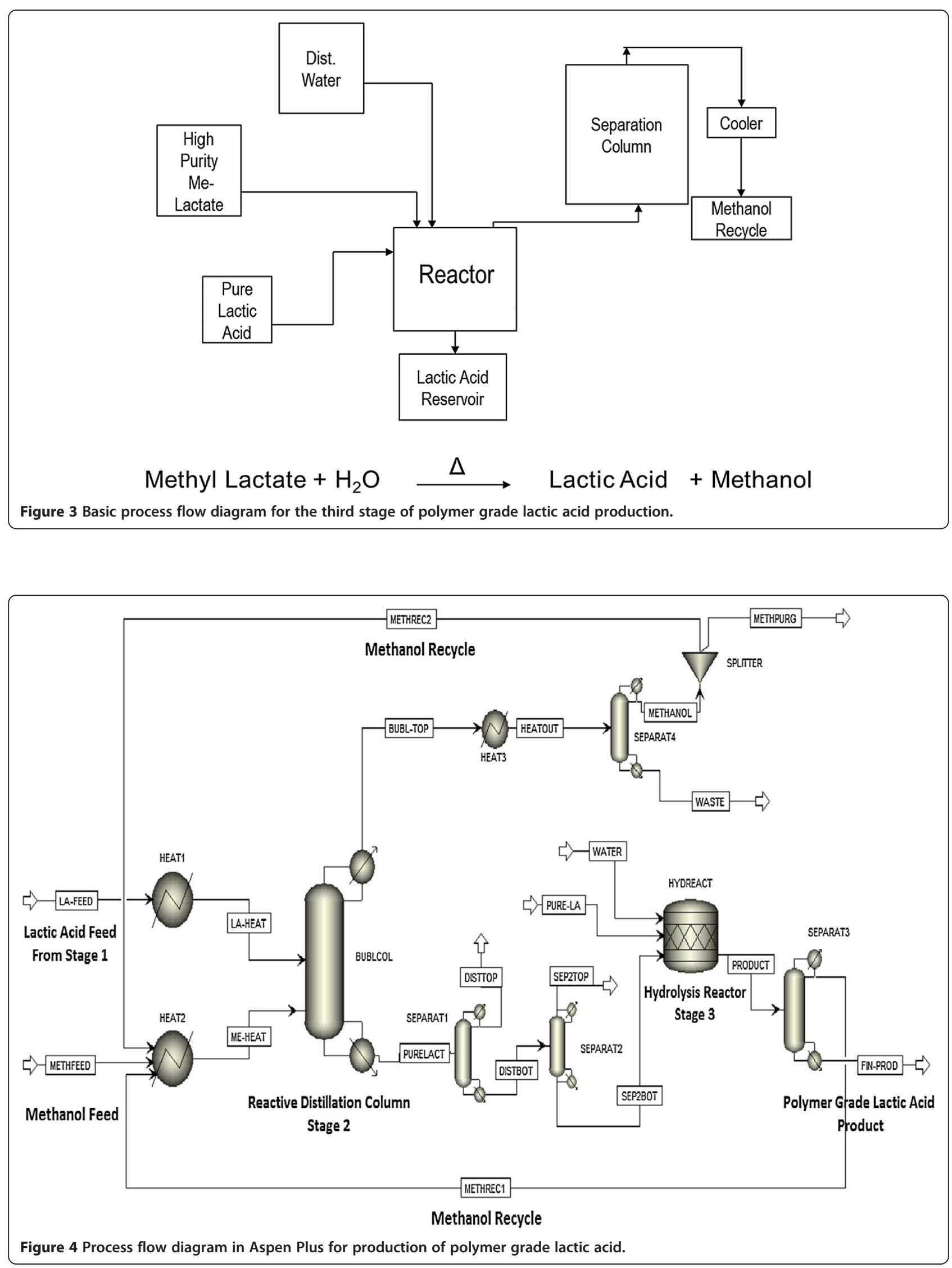
Table 2 Design basis obtained from patented process

\begin{tabular}{|c|c|c|}
\hline Equipment & Parameter & Values \\
\hline \multirow{5}{*}{$\begin{array}{l}\text { Bubble column } \\
\text { reactor }\end{array}$} & $\begin{array}{c}\text { Crude lactic } \\
\text { acid + Impurities }\end{array}$ & $1000 \mathrm{~g} / \mathrm{hr}$ \\
\hline & $\begin{array}{l}\text { Lactic acid feed } \\
\text { temperature }\end{array}$ & $369 \mathrm{~K}$ \\
\hline & Methanol + water & $750 \mathrm{~g} / \mathrm{hr}$ \\
\hline & $\begin{array}{l}\text { Methanol feed } \\
\text { temperature }\end{array}$ & $392 \mathrm{~K}$ \\
\hline & $\begin{array}{l}\text { Bottom section temp } \\
\text { of bubble column }\end{array}$ & $376 \mathrm{~K}$ \\
\hline \multirow[t]{2}{*}{ Separator } & $\begin{array}{l}\text { Highly pure } \\
\text { methyl lactate }\end{array}$ & $2500 \mathrm{~g} / \mathrm{hr}$ \\
\hline & $\begin{array}{l}\text { Distilled water } \\
\text { to reactor }\end{array}$ & $2500 \mathrm{~g} / \mathrm{hr}$ \\
\hline \multirow[t]{2}{*}{ Hydrolysis reactor } & $\begin{array}{l}\text { Pure lactic acid } \\
\text { to reactor }\end{array}$ & $500 \mathrm{~g} / \mathrm{hr}$ \\
\hline & Reactor temperature & $373 \mathrm{~K}$ \\
\hline
\end{tabular}

1. Thermodynamic model selection The majority of the process deals with highly polar components like lactic acid and methyl lactate, so the model must be based on the activity coefficient. In addition, lactic acid and methyl lactate both display non-ideal behavior which again indicates the requirement of an activity coefficient model. Therefore, initially the NRTL thermodynamic model was used as the thermodynamic property model for this process. But, the NRTL property model works well only for the vapor phase predictions of VLE. Hence, the Wilson-Hayden O'Connell property model was selected which provides accurate predictions for both phases in VLE.

2. Unit Operation Model selection

The first step in model development was to select the appropriate unit operation model based on the information available and the required output. For simulating the reactive distillation, RadFrac unit operation model is used. The RadFrac model can be used for rigorous fractionation, mainly for two or three phase vapor-liquid fractionation. Another advantage of RadFrac is the fact that it can handle chemical reactions, which is the case for reactive distillation column and also RadFrac can deal with strong liquid phase non-ideality. The hydrolysis reactor is modeled using the RStoich reactor. The main reason for selecting RStoich is that both conversion as well as stoichiometry was known for

Table 3 Summary of sensitivity analyses performed

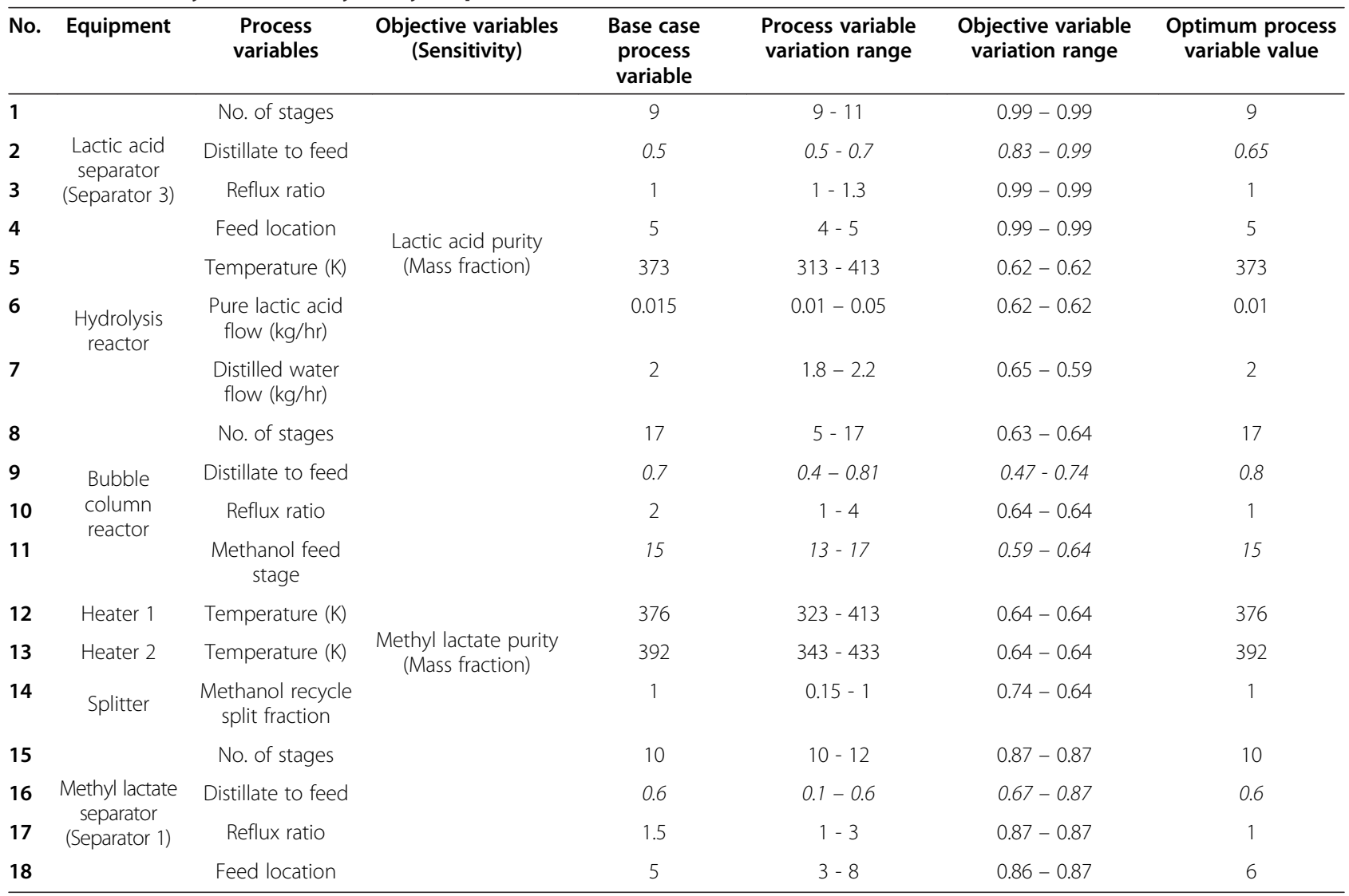

Note: Italicized numbers depict variables with significant variations over the range. 


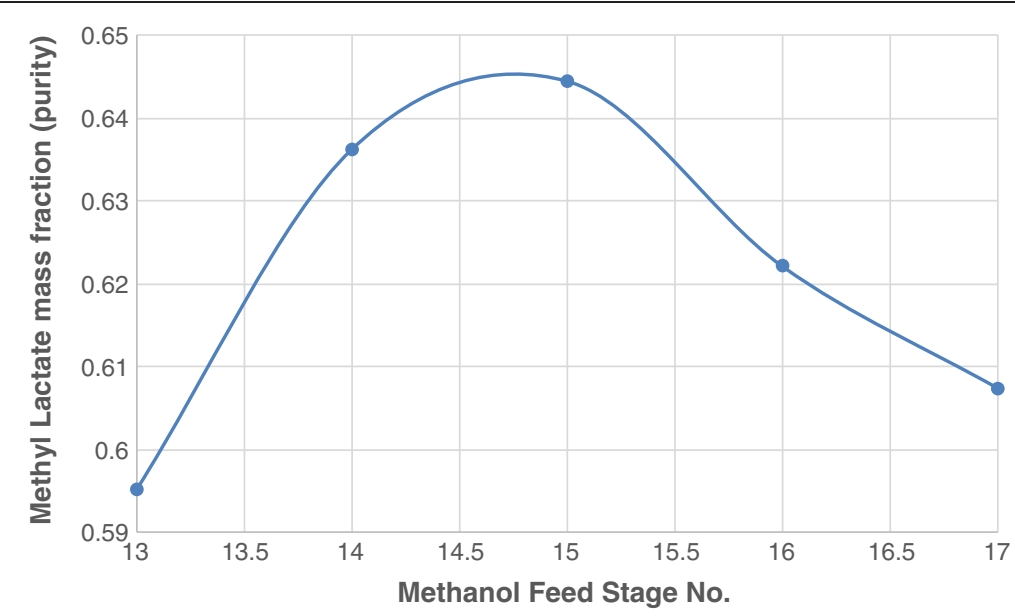

Figure 5 Sensitivity analysis results illustrating the effect of methanol feed stage variance in the bubble column reactor.

the reaction. Finally, Distl and Sep 2 model was used to simulate the two separators; the one used for isolating pure methyl lactate in stage 2 and the other used for separating pure lactic acid in stage 3 .

3. PFD generation

Based on the unit operation model selection, a basic process flow diagram (PFD) is generated in Aspen Plus $^{\oplus}$ (Figure 4).

4. Sensitivity Analysis

Sensitivity Analysis is a technique available in the Aspen Plus software which can be used to ascertain the effects of certain parameters on significant process variables. It can therefore be used to obtain optimum process conditions. In this technique different process parameters can be varied independently or simultaneously to study their effect on process variables like mass/mole fraction of desired product (mass/mole purity). In this work, sensitivity analyses has been performed for several objective variables including bubble column reactor and separator parameters- number of stages, distillate to feed ratio, reflux ratio, feed stage; hydrolysis reactor parameters - temperature, pure lactic acid flow, distilled water flow; methanol recycle split ratio.

\section{Results and discussion}

Sensitivity analyses were carried out for several objective variables as shown in Table 3. As can be observed from the table, methyl lactate and lactic acid purity (mass fraction) are the main objective variables. The sensitivity analyses were performed in a systematic manner for each of the major equipment - Bubble Column Reactor, Hydrolysis Reactor, Lactic Acid Separator (Separator 3), Methyl Lactate Separator (Separator 1), Methanol Recycle Splitter, Heater 1, and Heater 2. The process variables were varied to study their effect on objective variables. A

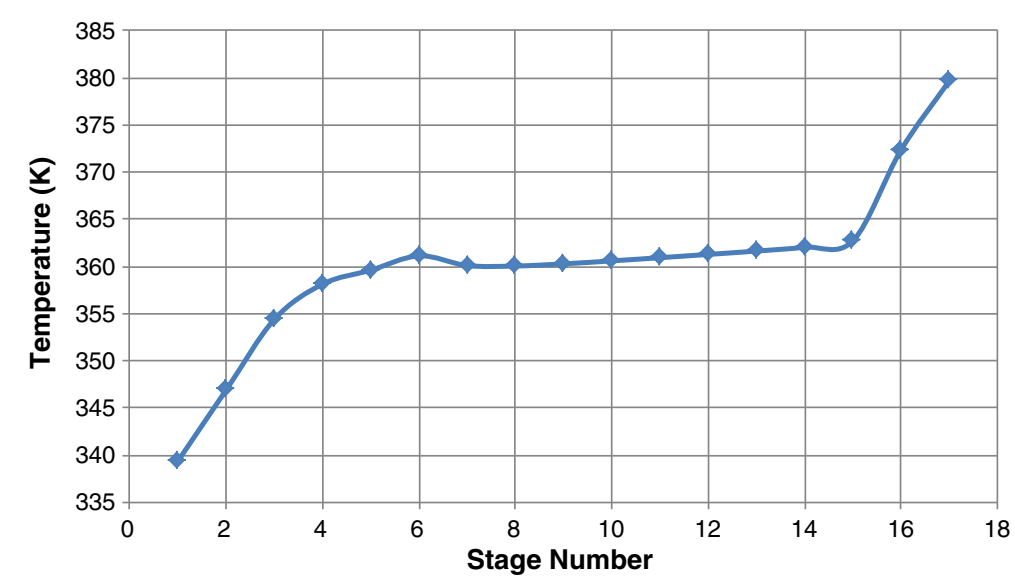

Figure 6 Temperature profile for the bubble column reactor (base case). 
Table 4 Stream results table (Base case)

\begin{tabular}{|c|c|c|c|c|c|c|c|c|}
\hline Parameter/stream $\rightarrow \downarrow$ & LA-FEED & METHFEED & PURELACT & DISTBOT & SEP2BOT & METHREC1 & PRODUCT & FIN-PROD \\
\hline Temperature (K) & 298.1 & 298.1 & 379 & 393.4 & 393.4 & 343.2 & 373.1 & 413.7 \\
\hline Pressure (atm.) & 1 & 1 & 1 & 1 & 1 & 1 & 1 & 1 \\
\hline Mass Fflow (kg/hr) & 10.5 & 7.5 & 11.29 & 8.171 & 6.921 & 2.445 & 8.936 & 6.491 \\
\hline \multicolumn{9}{|c|}{ Mass fraction (Mass purity) } \\
\hline Lactic acid & 0.571 & & 0.001 & 0.001 & & trace & 0.603 & 0.83 \\
\hline Methyl lactate & & & 0.613 & 0.845 & 0.997 & 147 PPM & 0.077 & 0.106 \\
\hline Methanol & & 0.996 & 0.003 & 62 PPB & & 0.782 & 0.214 & 165 PPM \\
\hline Water & 0.381 & 0.004 & 0.339 & 0.093 & 0.003 & 0.218 & 0.106 & 0.063 \\
\hline Others & 0.05 & & 0.045 & 0.059 & & & & \\
\hline
\end{tabular}

Note: 1) Italicized numbers depict variables with significant variations over the range.

2) Listed row headers depict streams and column headers depict parameters (As shown by arrows).

summary of the sensitivity analyses conducted and their results is illustrated in Table 3. The detailed tabulated results of the sensitivity analyses are provided in Additional file 1: Table S1-S6.

Using the data from sensitivity studies, optimum process conditions were determined for each major unit. The optimum was based on achieving the maximum purity for methyl lactate and lactic acid with minimum chemical inventory. In case of temperatures, if no significant change in purity was observed, the base case values from the patent have been used. In all other cases where no significant change in purity was observed, process conditions understandably leading to least costs (capital and operating) and energy consumption, were used.

It can be noted from Table 3 that the distillate to feed ratio has a significant effect on purity in the bubble column reactor as well as both the separators (Separator 1 and Separator 3). On the other hand, the reflux ratio and number of stages do not have any significant change on purity in any of the three units. Purity is sensitive towards methanol feed location in the bubble column reactor but is not affected by the feed location in either of the two separators.
It was observed that methyl lactate purity increases with an increase in methanol feed stage till stage no. 15 after which it marginally decreases (Figure 5). This observation was expected because as the methanol feed stage increases (column stage number increases from top to bottom), the contact time for methanol and lactic acid increases, thereby increasing mass transfer, subsequently resulting in higher purity of methyl lactate. Along with the sensitivity analysis, the bubble column temperature profile was obtained. The study of profile variations helped in determining the optimum feed stage for the methanol feed stream (Figure 6).

Stream results tables listing important streams with their process parameters for both the base case and optimized case have been illustrated in Tables 4 and 5 . Comparing the two tables the improvements in product purity in the optimum case becomes evident. Note that the stream names used are as specified in the process flow diagram.

\section{Conclusion}

A process flow diagram for the production of polymer grade lactic acid was developed using Aspen Plus ${ }^{\oplus}$. The

Table 5 Stream results table (Optimized case)

\begin{tabular}{|c|c|c|c|c|c|c|c|c|}
\hline Parameter/stream $\rightarrow \downarrow$ & LA-FEED & METHFEED & PURELACT & DISTBOT & SEP2BOT & METHREC1 & PRODUCT & FIN-PROD \\
\hline Temperature (K) & 298.1 & 298.1 & 382.4 & 414.6 & 414.6 & 346.6 & 373.1 & 489.8 \\
\hline Pressure (atm) & 1 & 1 & 1 & 1 & 1 & 1 & 1 & 1 \\
\hline Mass flow (kg/hr) & 10.5 & 7.5 & 11.056 & 8.625 & 8.072 & 4.129 & 10.122 & 5.993 \\
\hline \multicolumn{9}{|c|}{ Mass fraction (Mass purity) } \\
\hline Lactic acid & 0.571 & & 730 PPM & 935 PPM & & 0.079 & 0.624 & 1 \\
\hline Methyl lactate & & & 0.733 & 0.933 & 0.997 & 0.195 & 0.08 & 41 PPM \\
\hline Methanol & & 0.996 & 0.005 & 302 PPB & & 0.54 & 0.22 & 4 PPB \\
\hline Water & 0.381 & 0.004 & 0.216 & 0.009 & 0.003 & 0.186 & 0.076 & 57 PPB \\
\hline Others & 0.05 & & 0.045 & 0.059 & & & & \\
\hline
\end{tabular}

Note: 1) Italicized numbers depict variables with significant variations over the range.

2) Listed row headers depict streams and column headers depict parameters (As shown by arrows). 
process was successfully simulated and converged results were obtained. An extensive sensitivity analysis was conducted on each of the key pieces of equipment to obtain high purity methyl lactate and subsequently pure lactic acid. The process conditions were subsequently optimized based on these results. The desired purity of polymer grade lactic acid ( 99 wt. \%, dry basis) was obtained. Also, the purity of methyl lactate was above the desired percentage of $98.5 \mathrm{wt}$ \%.

\section{Additional file}

Additional file 1: Table S1. Sensitivity analyses results over Separator 3 for Lactic acid (LA) mass fraction by varying Distillate to feed ratio, Reflux Ratio, Feed Location and No. of Stages. Table S2. Sensitivity analyses results over Hydrolysis Reactor for Lactic acid (LA) mass fraction by varying Reactor Temperature, Pure Lactic Acid Inlet Flow Rate and Distilled Water Flow rate. Table S3. Sensitivity analyses results over Bubble Column Reactor for Methyl Lactate (Me-La) mass fraction by varying No. of Stages, Distillate to feed ratio, Reflux Ratio and Methanol Feed Location. Table S4. Sensitivity analyses results over Bubble Column Reactor for Methyl Lactate (Me-La) mass fraction by varying Heater 1 (Lactic Acid Feed) Temperature, Heater 2 (Methanol Feed) Temperature. Table S5. Sensitivity analyses results over Splitter for Methyl Lactate (Me-La) mass fraction by varying methanol split fraction. Table $\mathbf{S 6 .}$ Sensitivity analyses results over Separator 1 for Methyl Lactate (Me-La) mass fraction by varying Distillate to feed ratio, Reflux Ratio, Feed Location and No. of Stages.

\section{Competing interests}

The authors declare no competing financial interests.

\section{Authors' contributions}

SSB performed process simulations and optimization studies for the process presented in the paper. SSB drafted the manuscript in collaboration with CPA. CPA provided consultation regarding the process simulations and optimization. CPA drafted the manuscript in collaboration with SSB. KAH provided consultation regarding the process simulations and optimization. $\mathrm{KAH}$ reviewed the manuscript. All authors read and approved the final manuscript.

\section{Acknowledgement}

The authors would like to express their sincere acknowledgments to Dr. Sayeed Mohammad, School of Chemical Engineering, Oklahoma State University for providing timely assistance during this work.

\section{Received: 23 September 2013 Accepted: 27 January 2014}

Published: 3 February 2014

\section{References}

1. Datta R, Henry M: Lactic acid: recent advances in products, processes and technologies - a review. J Chem Technol Biotechnol 2006, 81(7):1119-1129. doi:10.1002/jctb. 1486.

2. Guilherme A, Silveira M, Fontes C, Rodrigues S, Fernandes F: Modeling and optimization of lactic acid production using cashew apple juice as substrate. Food Bioprocess Technol 2012, 5(8):3151-3158. doi:10.1007/s11947-011-0670-z.

3. Södergård A, Stolt M: Industrial Production of High Molecular Weight Poly (Lactic Acid). In Poly (Lactic Acid): Synthesis, Structures, Properties, Processing, and Applications. Edited by Auras R, Lim L-T, Selke SEM, Tsuji H. Hoboken, NJ, USA: John Wiley \& Sons, Inc; 2010. doi:10.1002/ 9780470649848.ch3.

4. Garlotta D: A literature review of poly(lactic acid). J Polym Environ 2001, 9(2):63-84. doi:10.1023/A:1020200822435.

5. Qin J, Zhao B, Wang X, Wang L, Yu B, Ma Y, Xu P: Non-sterilized fermentative production of polymer-grade L-lactic acid by a newly isolated thermophilic strain Bacillussp. PLOS ONE 2009, 4(2):e4359. doi:10.1371/journal.pone.0004359
6. John R, Nampoothiri K, Pandey A: Fermentative production of lactic acid from biomass: an overview on process developments and future perspectives. App/ Microbiol Biotechnol 2007, 74(3):524-534. doi:10.1007/ s00253-006-0779-6.

7. Mehta R, Kumar V, Bhunia H, Upadhyay S: Synthesis of poly(lactic acid): a review. J Macromol Sci Part C 2005, 45(4):325-349. doi:10.1080/ 15321790500304148.

8. Tolinski M: Plastics and Sustainability - Towards a Peaceful Coexistence between Bio-Based and Fossil Fuel-Based Plastics. Salem, Massachussetts: Wiley-Scrivener; 2012.

9. Tabone M, Cregg J, Beckman E, Landis A: Sustainability metrics: life cycle assessment and green design in polymers. Environ Sci Technol 2010, 44(21):8264-8269.

10. Henry W: Purifying hydroxyl-aliphatic acids, United States Patent 2334524. New York; 1943

11. Schopmeyer H, Arnold C: Lactic Acid Purification. Maine: United States Patent 2350370; 1944

12. Weisberg S, Stimpson E: Preparation of Lactic Acid, United States Patent 2290926. Baltimore, Maryland; 1942.

13. Barve P, Kulkarni B, Nene S, Shinde R, Gupte M, Joshi C, Thite G, Chavan V, Deshpande T: Process for Preparing L(+)-Lactic Acid. Maharashtra, India: United States Patent 7820859 B2; 2010.

14. Stichlmair J, Frey T: Reactive distillation processes. Chem Eng Technol 1999, 22 (2):95-103. doi:10.1002/(SICl)1521-4125(199902)22:2<95:AID-CEAT95>3.0.CO;2-\#.

15. Hauan S, Lien K: A phenomena based design approach to reactive distillation. Chem Eng Res Des 1998, 76(3):396-407.

doi:10.1186/2043-7129-2-3

Cite this article as: Bapat et al: Development of a sustainable process for the production of polymer grade lactic acid. Sustainable Chemical Processes 2014 2:3.

\section{Publish with ChemistryCentral and every scientist can read your work free of charge \\ "Open access provides opportunities to our colleagues in other parts of the globe, by allowing anyone to view the content free of charge." W. Jeffery Hurst, The Hershey Company. \\ - available free of charge to the entire scientific community \\ - peer reviewed and published immediately upon acceptance \\ - cited in PubMed and archived on PubMed Central \\ - yours - you keep the copyright \\ Submit your manuscript here: \\ http://www.chemistrycentral.com/manuscript/<smiles>c1ccccc1</smiles> \\ Chemistry Central}

